Electronic Supplementary Information

\title{
Fullerene-Like Polyoxotitanium Cage with High Solution Stability
}

Mei-Yan Gao, Fei Wang, Zhi-Gang Gu, De-Xiang Zhang, Lei Zhang ${ }^{*}$ and Jian Zhang ${ }^{*}$

State Key Laboratory of Structural Chemistry, Fujian Institute of Research on the Structure of Matter, Chinese Academy of Sciences, 350002 Fuzhou, P. R. China

E-mail: LZhang@fjirsm.ac.cn and zhj@fjirsm.ac.cn 
Materials and Instrumentation. All the reagents and solvents employed were commercially available and were used as received without further purification. Fourier transform infrared spectroscopy (FTIR) data were collected on a PerkinElmer Spectrum 100 FT-IR Spectrometer. UV-Vis absorption spectra were measured on a Perkin-Elmer Lambda 35 UV-Vis spectrophotometer. ESI-MS was carried out on Thermo Scientific Exactive Plus. Powder X-ray diffraction (PXRD) analysis was performed on a MiniFlex2 X-ray diffractometer using $\mathrm{Cu}-\mathrm{K} \alpha$ radiation $(\lambda=0.1542$ $\mathrm{nm})$ in the $2 \theta$ range of $5-20^{\circ}$ with a scanning rate of $0.5^{\circ} \mathrm{min}^{-1}$. The thermogravimetric analyses (TGA) were performed on a Mettler Toledo TGA/SDTA $851^{\mathrm{e}}$ analyzer in $\mathrm{N}_{2}$ atmosphere with a heating rate of $10^{\circ} \mathrm{C} / \mathrm{min}$ from $30^{\circ} \mathrm{C}$ to $800{ }^{\circ} \mathrm{C}$. ${ }^{1} \mathrm{H}$ NMR (400 MHz) spectrum was recorded in 1,2-Dichlorobenzene-d4 $\left(\mathrm{C}_{6} \mathrm{D}_{4} \mathrm{Cl}_{2}\right)$ solution using a Burker AVANCE 400 spectrometer.

\section{Synthesis of TOF-1:}

$\mathrm{Ti}\left(\mathrm{O}_{\mathrm{i}} \mathrm{Pr}\right)_{4}(0.92 \mathrm{ml}, 3.0 \mathrm{mmol})$ and 5 drops of formic acid were added to isopropyl alcohol $(5.5 \mathrm{ml})$ and mixed at room temperature. The resultant solution was heated at $100^{\circ} \mathrm{C}$ for four days. After cooled to room temperature, colorless crystals of TOF-1 were obtained. Yield: $\sim 100 \mathrm{mg}$ (about $40 \%$ based on Ti).

\section{Fabrication of TOF-1@HKUST-1 thin film:}

Mass spectra (Figure S8) of TOF-1 solution shows this cluster core is very stable in solution status, demonstrating that it is suitable for in situ encapsulation into the cavities of HKUST-1 using LPE layer-by-layer fashion (Figure S9).

Using the Liquid phase epitaxial spray method, TOF-1@HKUST-1 thin film was grown on OH-terminated Si substrate along [111] orientation.

The TOF-1@HKUST-1 thin film was fabricated using the following diluted ethanolic solutions (Figure S10): copper acetate $(1 \mathrm{mM})$ and BTC $(0.4 \mathrm{mM})$ and TOF-1 $(0.1 \mathrm{mM})$. The spray times were $15 \mathrm{~s}, 25 \mathrm{~s}$ and $10 \mathrm{~s}$ for $\mathrm{Cu}(\mathrm{OAc})_{2}$, BTC and TOF-1 solution, respectively. There was waiting time for 30 s between steps and each step was followed by a $3 \mathrm{~s}$ spray step with pure ethanol to remove residual reactants. A 
total of 60 growth cycles were used for in situ LPE layer-by-layer TOF-1 encapsulation in HKUST-1 thin film in this work.

X-ray Crystallography: Crystallographic data of TOF-1 was collected on a Supernova single crystal diffractometer equipped with graphite-monochromatic $\mathrm{Cu}$ $\mathrm{K} \alpha$ radiation $(\lambda=1.54178 \AA)$ at $273 \mathrm{~K}$. Absorption correction was applied using SADABS. ${ }^{1}$ Structure was solved by direct method and refined by full-matrix least-squares on $\mathrm{F}^{2}$ using SHELXTL. ${ }^{2}$ Because of the low diffraction intensity, the $\mathrm{C}$ and $\mathrm{H}$ atoms were highly disordered and could not be located. Contributions to scattering due to disordered solvent molecules were removed using the SQUEEZE routine of PLATON; ${ }^{3}$ structures were then refined again using the data generated. Crystal data and details of data collection and refinement of TOF-1 were summarized in Table S1.

CCDC 1439830 contains the supplementary crystallographic data for this paper. This data are provided free of charge by The Cambridge Crystallographic Data Centre.

(1) G. M. Sheldrick, SADABS, Program for area detector adsorption correction. Institute for Inorganic Chemistry, University of Göttingen, Göttingen (Germany), 1996.

(2) G. M. Sheldrick, SHELXL-97, Program for solution of crystal structures. University of Göttingen, Göttingen (Germany), 1997.

(3) P. Vandersluis, A. L. Spek, Acta Crystallogr. A 1990, 46, 194. 
Table S1. Crystal data and structure refinement summary for TOF-1.

\begin{tabular}{|c|c|}
\hline CCDC No & 1439830 \\
\hline Formula & $\mathrm{C}_{126} \mathrm{H}_{312} \mathrm{O}_{114} \mathrm{Ti}_{42}$ \\
\hline $\mathrm{Mr}$ & 5662.16 \\
\hline crystal system & cubic \\
\hline space group & $\mathrm{Fm}-3$ \\
\hline$a[\AA]$ & 29.8960 \\
\hline$\alpha\left[^{0}\right]$ & 90.00 \\
\hline$V\left[\AA^{3}\right]$ & 26720.2 \\
\hline Z & 1 \\
\hline $\mathrm{T}[\mathrm{K}]$ & 293 \\
\hline$\rho_{\mathrm{c}}\left[\mathrm{gcm}^{-3}\right]$ & 0.953 \\
\hline$\mu\left[\mathrm{mm}^{-1}\right]$ & 10.516 \\
\hline reflns coll. & 4928 \\
\hline unique reflns & 2251 \\
\hline GOF & 0.909 \\
\hline$R 1[I>2 \sigma(I)]^{[\mathrm{a}]}$ & 0.1244 \\
\hline$w R 2[I>2 \sigma(I)]^{[\mathrm{b}]}$ & 0.3063 \\
\hline
\end{tabular}
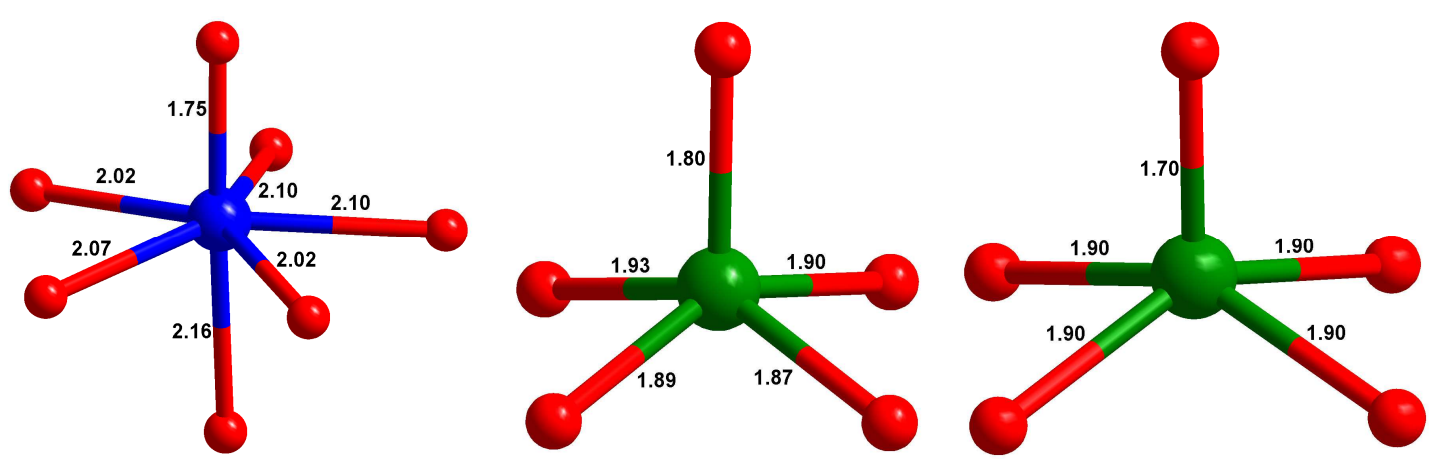

Figure S1. The cooorindation enviorenments of Ti1 (left), Ti2 (middle), Ti3 (right) in TOF-1, showing the Ti-O bond lenths $(\AA)$. 


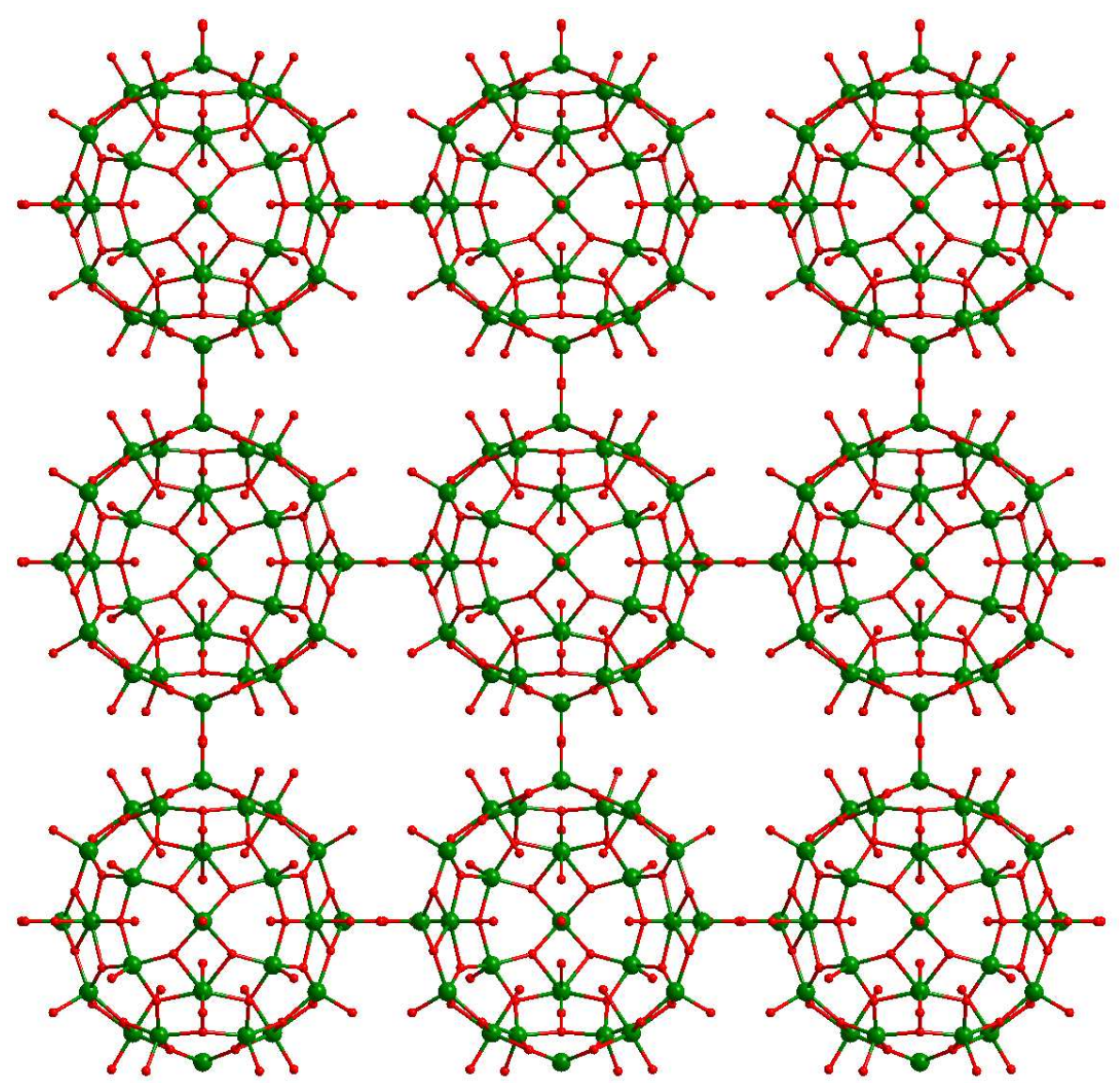

Figure S2. Packing model of TOF-1, along the $c$-axis.
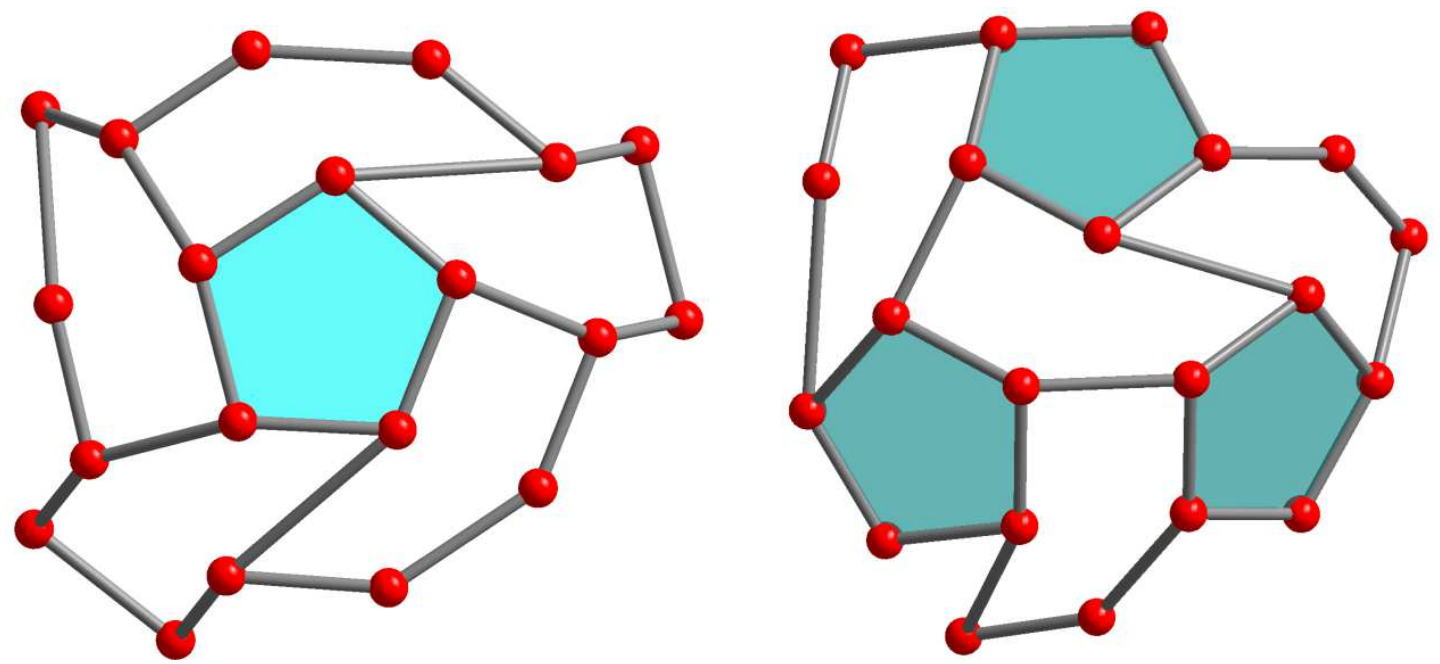

Figure S3. The illustrations of the five distorted $\left\{\mathrm{O}_{6}\right\}$ rings around the $\left\{\mathrm{O}_{5}\right\}$ pentagon (left), and the three $\left\{\mathrm{O}_{5}\right\}$ pentagons and three $\left\{\mathrm{O}_{6}\right\}$ rings around the $\left\{\mathrm{O}_{6}\right\}$ ring (right). 


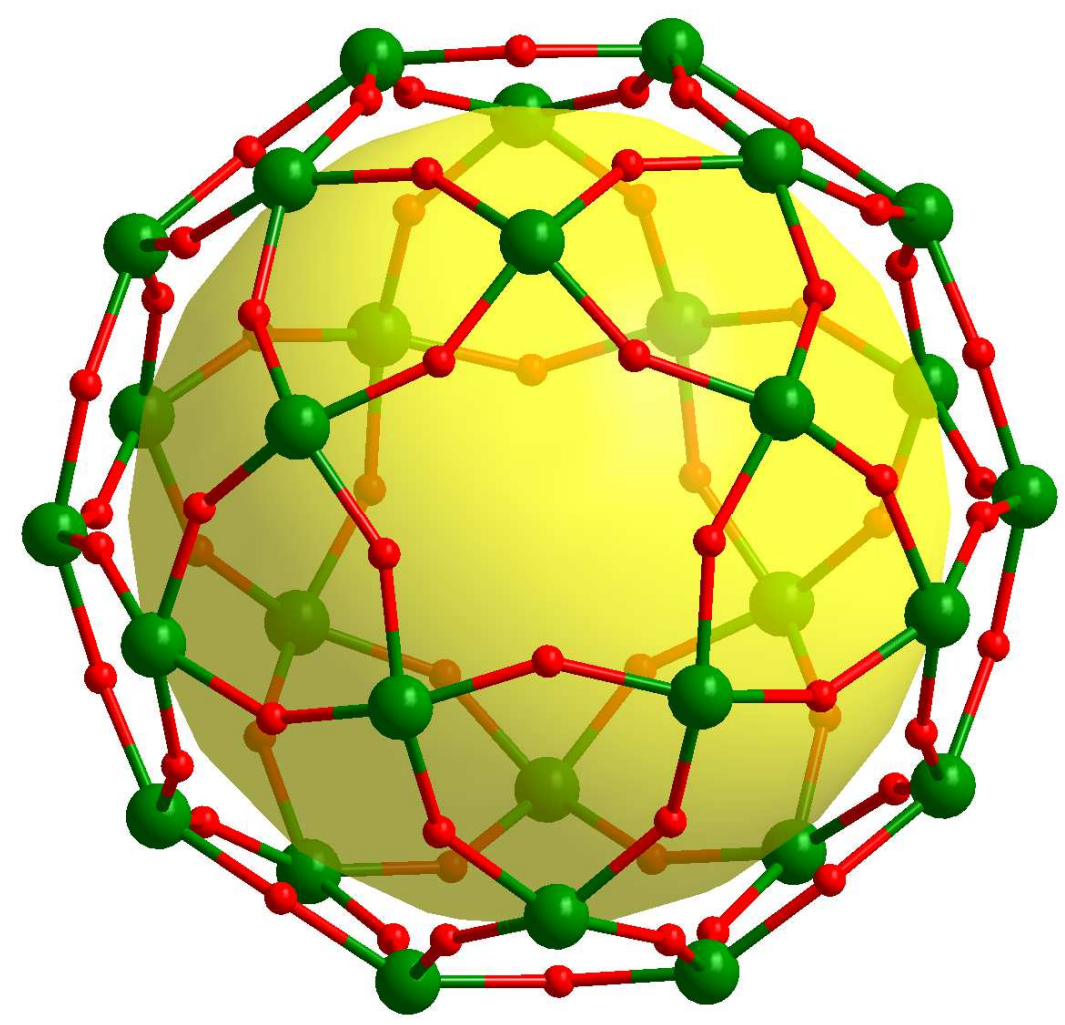

Figure S4. The $\left\{\mathrm{Ti}_{30} \mathrm{O}_{60}\right\}$ sphere consisted of the 30 tetragonal-pyramid coordinated $\mathrm{Ti}^{4+}$ ions and the $60 \mu_{3}-\mathrm{O}^{2-}$ ions.

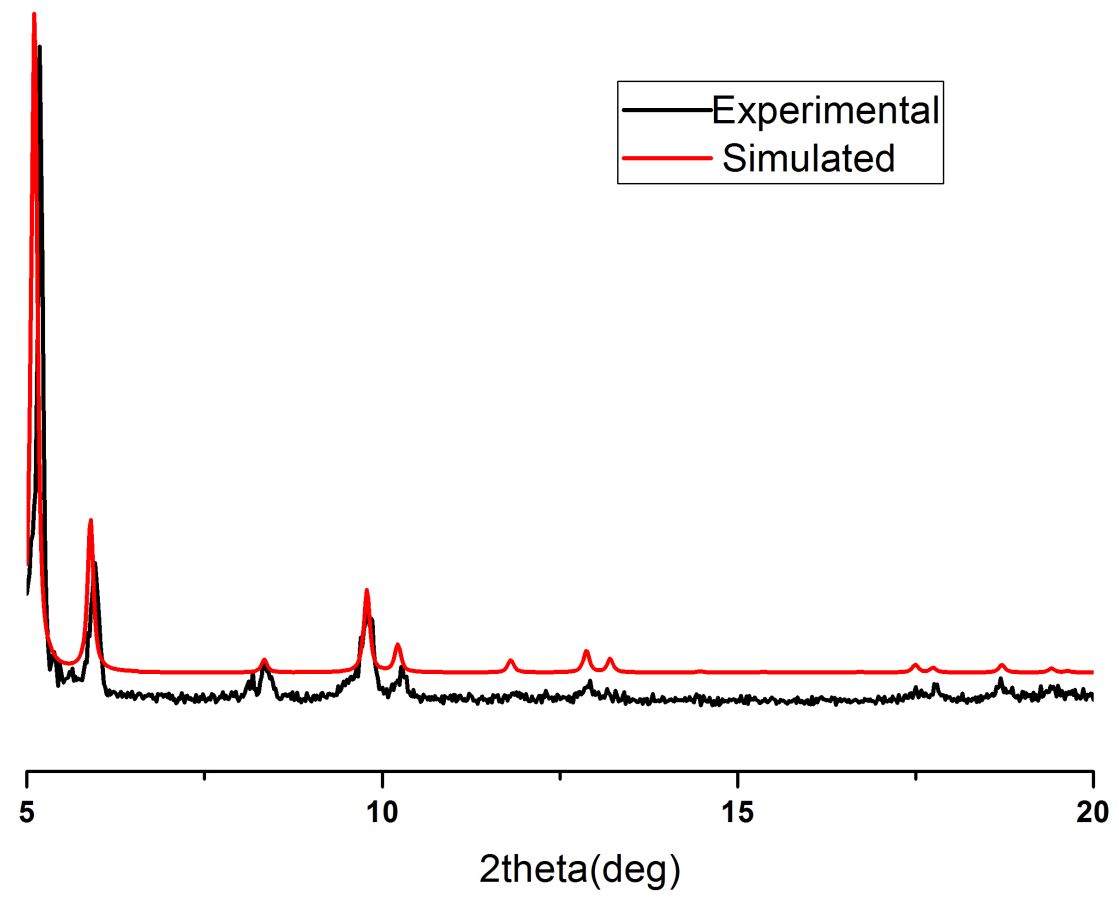

Figure S5. The powder X-ray diffraction (PXRD) pattern for TOF-1, confirming its phase purity. 


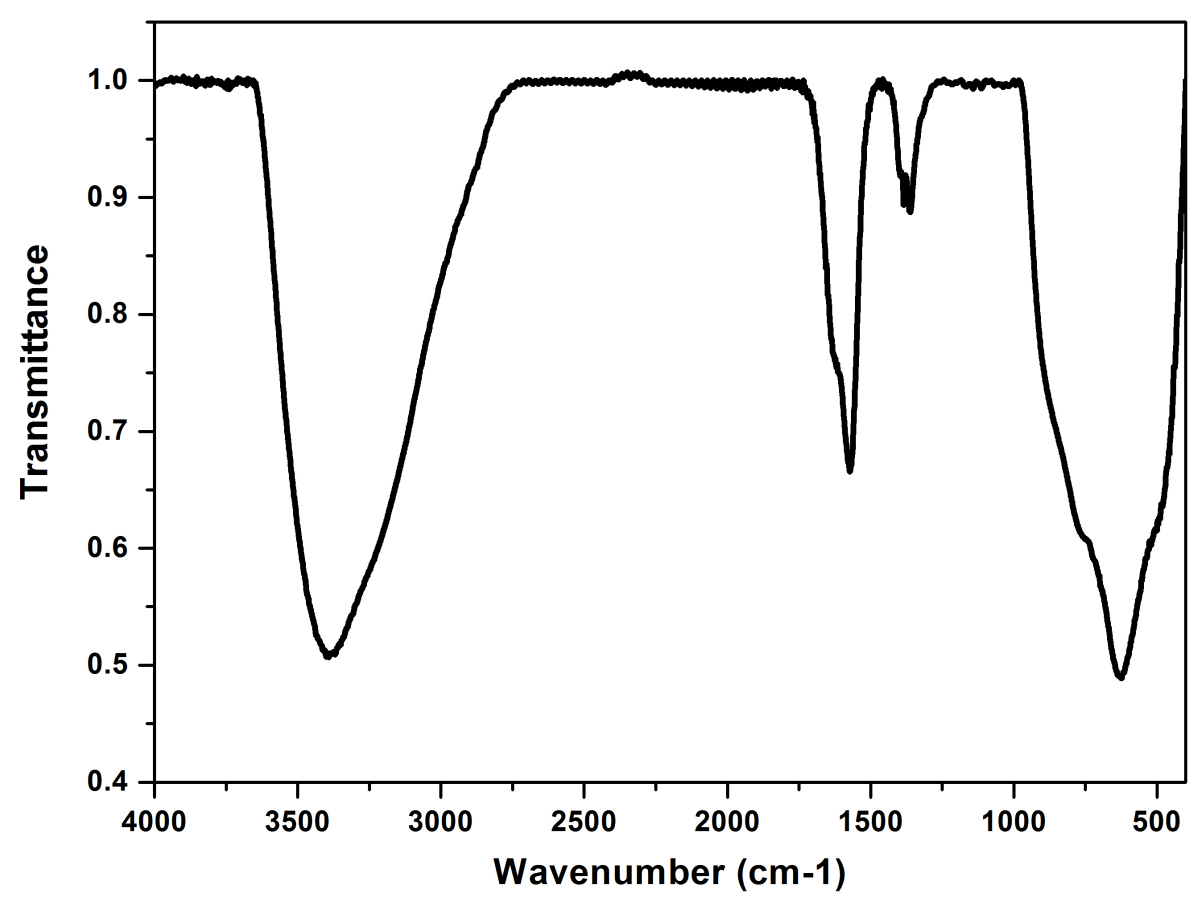

Figure S6. FT-IR spectrum for TOF-1.

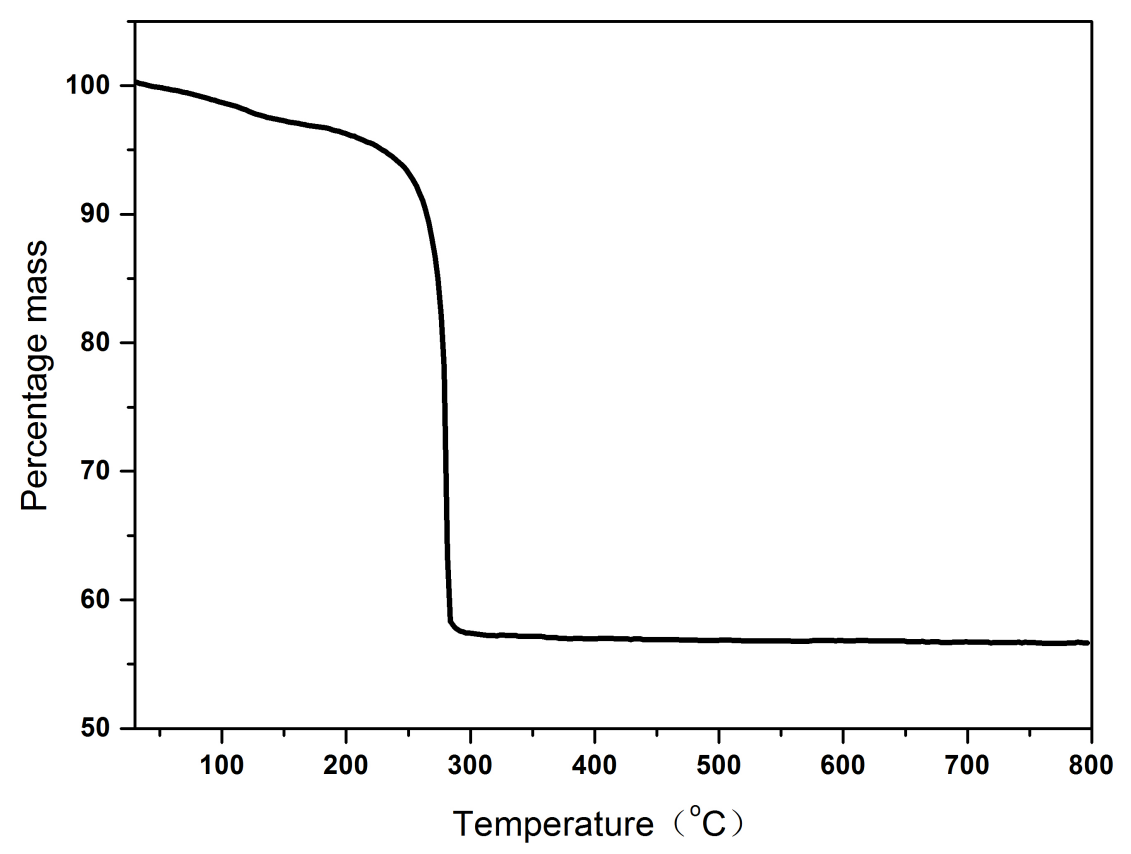

Figure S7. TGA analysis of TOF-1. The weight loss between 30 and $300{ }^{\circ} \mathrm{C}$ should be attributed to the decomposition of the 42 isopropoxo ligands. The calculated loss is $43.83 \%$, and the observed loss is $42.60 \%$. 


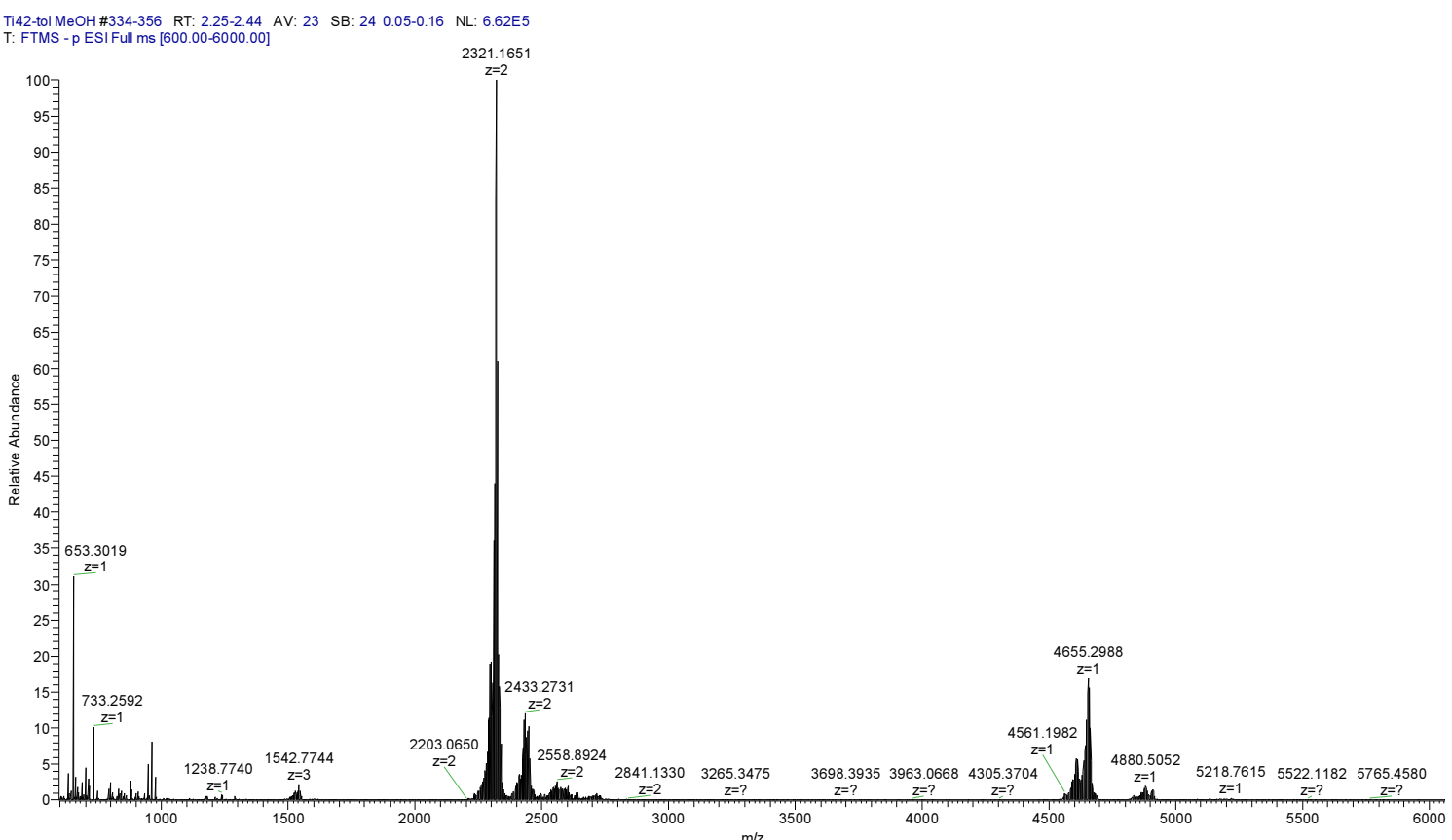

Figure S8. ESI-MS spectrum of TOF-1 in toluene/methanol solution. Samples were dissolved and kept in toluene before MS analysis, which was diluted by methanol and immediately injected into the MS instrument.

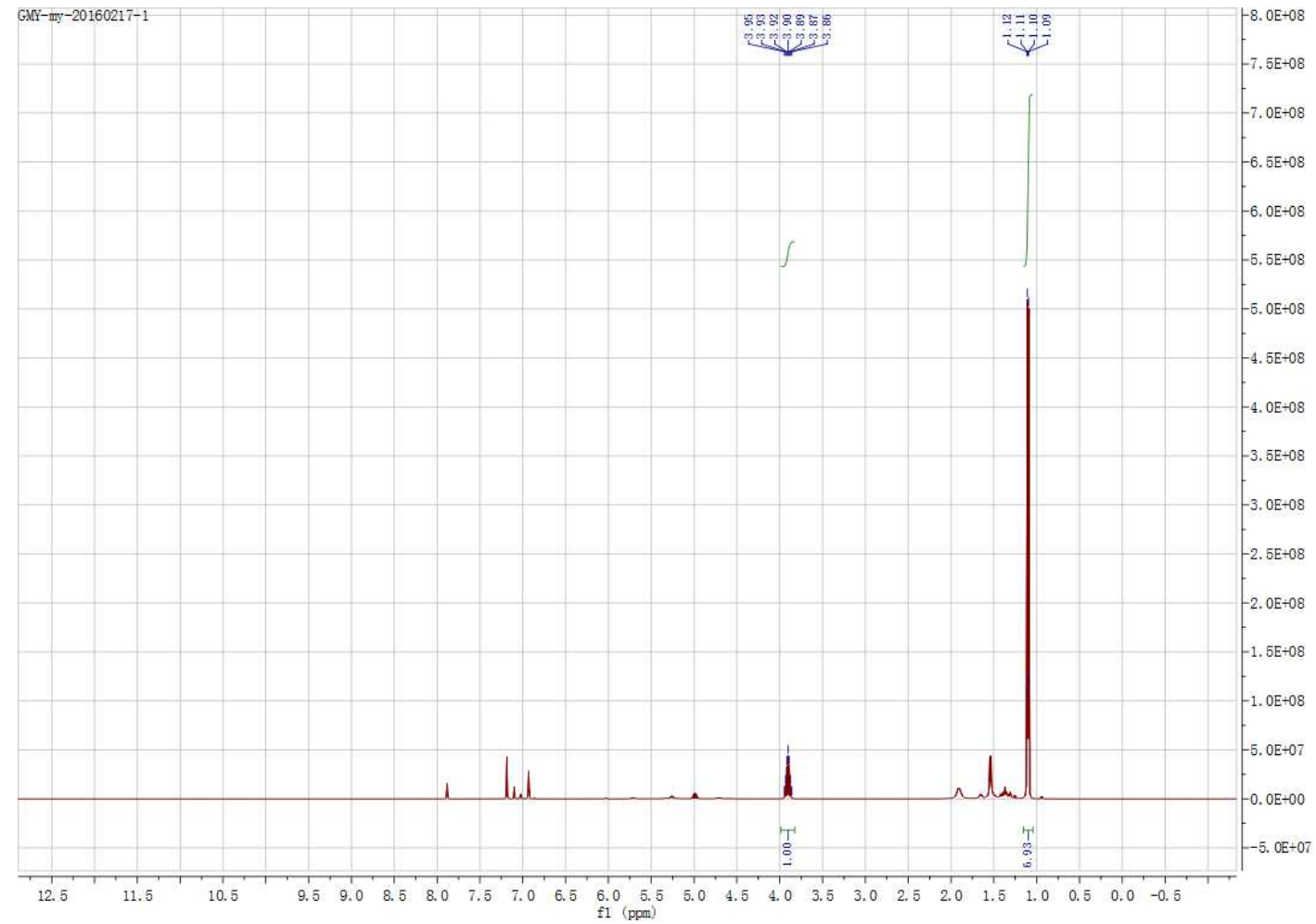

Figure S9. ${ }^{1} \mathrm{H}$ NMR spectrum of TOF-1 dissolved in 1,2-Dichlorobenzene-d4 $\left(\mathrm{C}_{6} \mathrm{D}_{4} \mathrm{Cl}_{2}\right)$. 


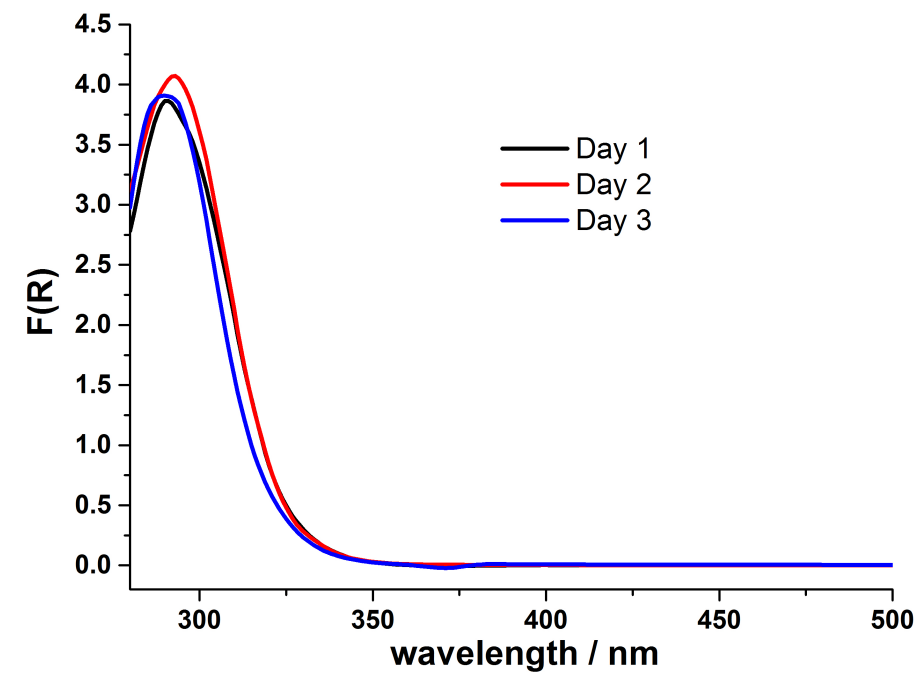

Figure S10. Solution electronic absorption spectra of TOF-1 in toluene $(0.3 \mathrm{M})$ recorded in different time.
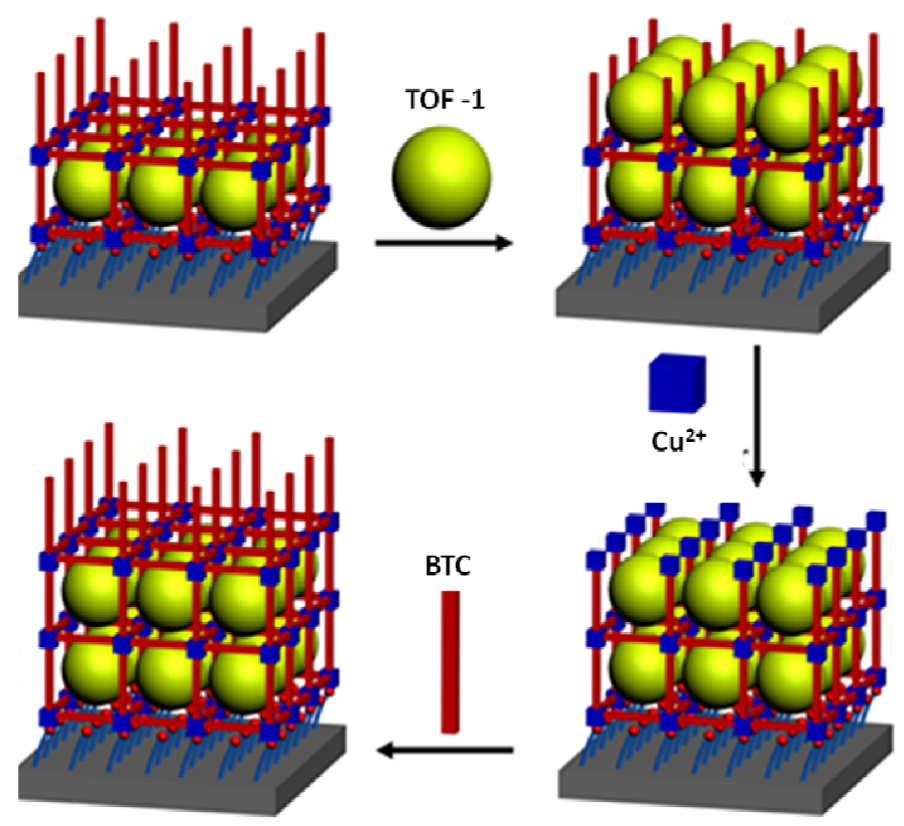

Figure S11. Schematic presentation of in situ layer-by-layer growth of TOF-1 loaded HKUST-1 thin film using the liquid phase epitaxy (LPE) approach (adapted from ref. 28). 


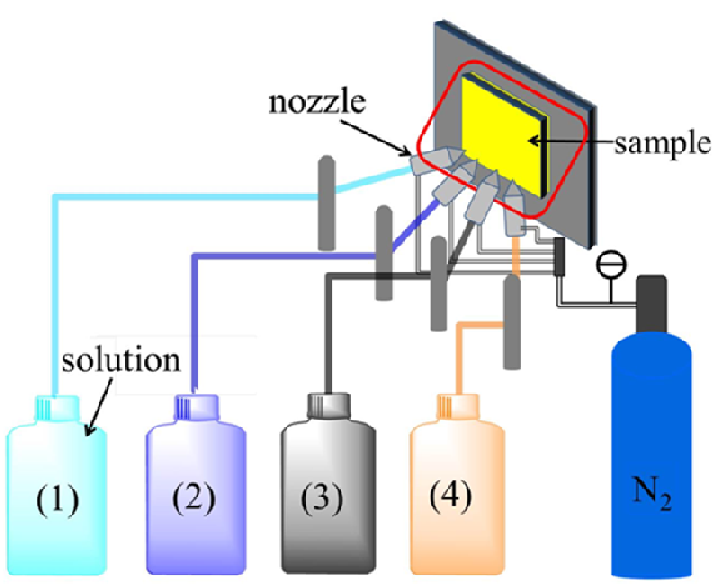

(1)

(3)

(2)

(3)

(4)

(3)

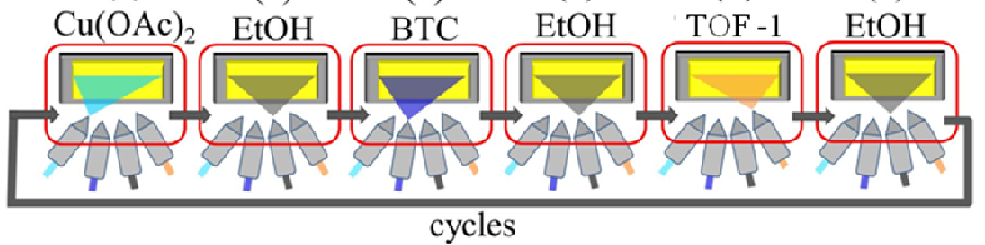

Figure S12. Schematic presentation of in situ layer-by-layer growth of TOF-1@HKUST-1 thin film using the liquid phase epitaxy (LPE) approach (adapted from ref. 28).

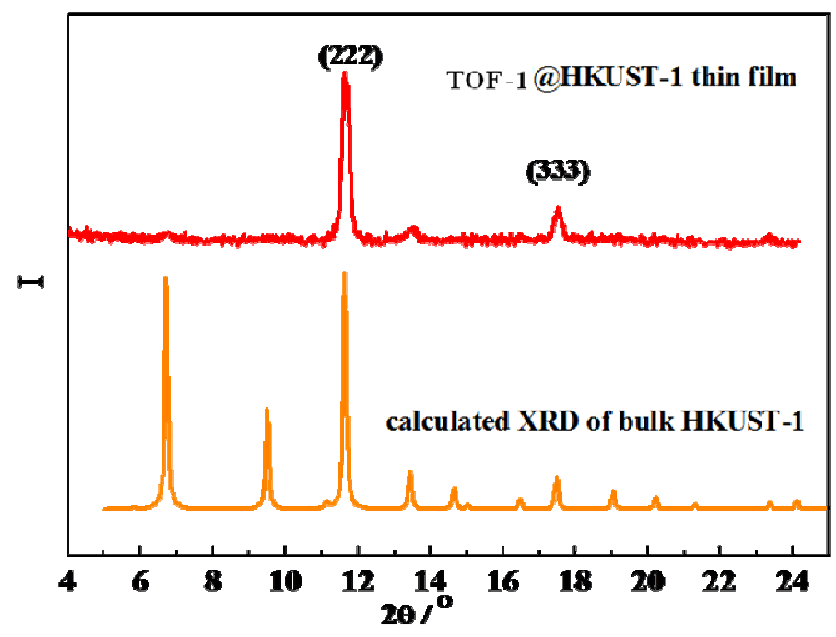

Figure S13. Experimental XRD pattern of TOF-1@HKUST-1 thin film and calculated XRD pattern of crystalline HKUST-1. The absence of diffraction peaks for other HKUST-1 orientations demonstrated the presence of an oriented thin film, with the [111] orientation perpendicular to the substrate. 

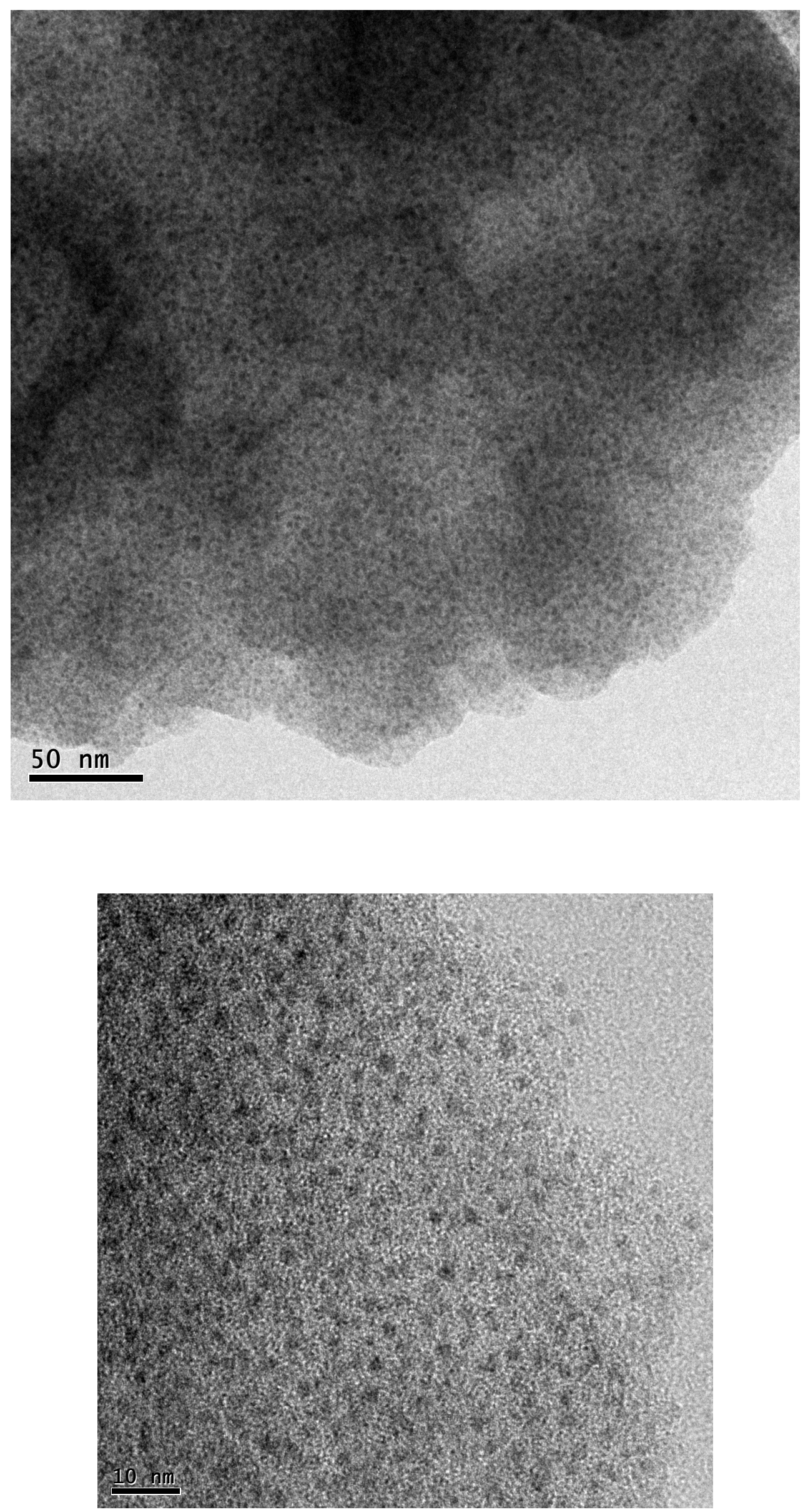


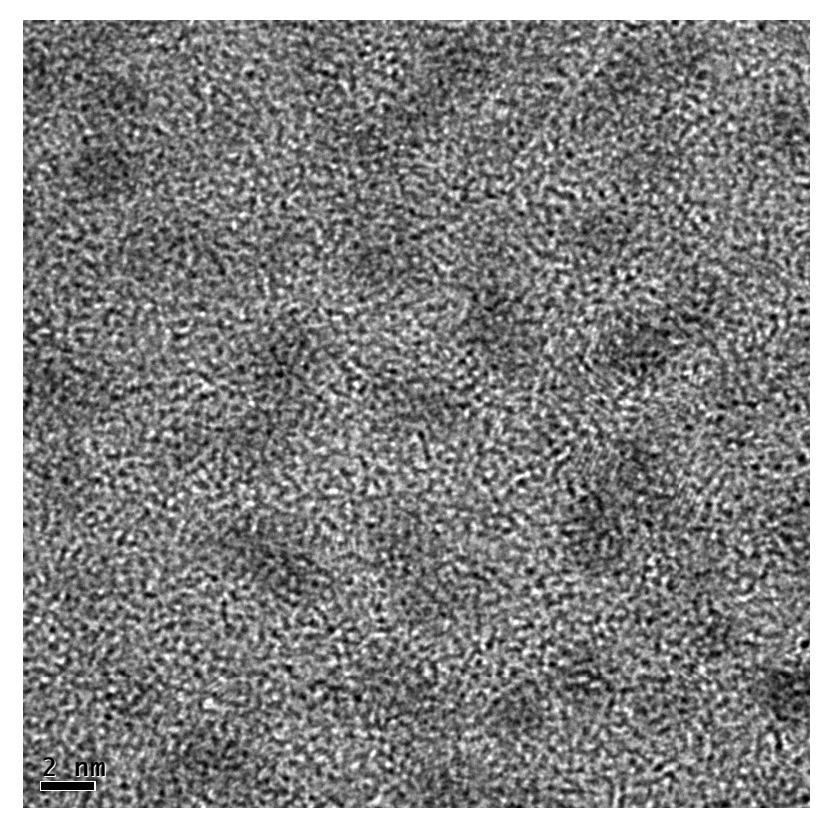

Figure S14. TEM images of the TOF-1@HKUST-1 thin film. 